\title{
ASPECTOS (BIO)ÉTICOS NA INTERAÇÃO PROFESSOR-ALUNO EM MANIFESTAÇÕES À OUVIDORIA
}

\author{
Maria Elisa Freire Meneghini ${ }^{1}$ \\ Ana Maria Lombardi Daibem²
}

\begin{abstract}
Resumo
Este artigo aborda parte do estudo que teve como objetivo conhecer a representação sobre as relações de poder na universidade articulada por alunos que se manifestaram via Ouvidoria; eleger critérios de bioética para leitura e análise de manifestações que revelam relações de poder; e apreender e analisar os questionamentos que denotam relações de poder na ação pedagógica e os possíveis impactos na formação técnica e cidadã do aluno. A metodologia utilizada compreendeu a pesquisa bibliográfica, que permitiu ampliar a visão sobre os temas abordados, sendo os dados analisados por meio da Análise de Conteúdo. Além do contributo bioético, a teoria sociológica de Pierre Bourdieu deu suporte à análise do conteúdo das manifestações, pois trata do poder e da violência simbólicos nas relações que se dão no campo da educação, em reflexões que englobam a dignidade e os direitos humanos. As percepções advindas dos conflitos relatados abrangendo relações assimétricas de poder e aspectos bioéticos contribuem para a hipótese formulada acerca do problema de retenção do aluno, postergando a sua entrada na vida profissional, ou, até mesmo, a desistência da vida acadêmica. Ainda, as questões reclamadas tanto no plano comunicacional entre professor e aluno quanto as que se referem a qualidade do ensino oferecido, com comprometimento de princípios e valores institucionais, indicam possíveis influências nas competências humana e técnica do profissional formado pela universidade. Todavia, para confirmar essas percepções e avaliar em que dimensão elas ocorrerem, há necessidade de novos estudos apontando nessa direção.
\end{abstract}

Palavras-Chave: Ouvidoria. Bioética. Universidade. Relação de poder.

DOI:10.37814/2594-5068.2020v3.p133-145

1 Farmacêutica Bioquímica. Doutoranda em Bioética. Mestra em Patologia Tropical. Especialista em Gestão de Ouvidorias. Docente e ex-Ouvidora (2011-2015) na Universidade Federal do Amazonas. (meneghini@ufam.edu.br)

2 Pedagoga. Doutora e Mestra em Educação. Docente no Centro Universitário São Camilo. (amdaibem@gmail.com) 


\begin{abstract}
This article discusses part of the study which objective was to know the representation on the power relations in the university articulated by students who manifested themselves through Ombudsman; to elect criteria of bioethics for reading and analysis of manifestations that reveal relations of power; and to apprehend and analyze the questions that denote power relations in the pedagogical action, and the possible impacts on the technical and citizen training of the student. The methodology used included the bibliographic research, which allowed to broaden the view on the topics addressed, being the data analyzed through Content Analysis. In addition to the bioethical contribution, the sociological theory of Pierre Bourdieu supported the analysis of the content of the demonstrations, since it deals with symbolic power and violence in the relations that take place in the field of education, in reflections that encompass dignity and human rights. The perceptions arising from the reported conflicts, covering asymmetric relations of power and bioethical aspects, contribute to the hypothesis formulated about the problem of student retention, delaying their entry into professional life, or even the abandonment of academic life. In addition, questions raised in the communication between teacher and student, as well as those related to the quality of teaching offered, compromising institutional principles and values, indicate possible influences on the human and technical competencies of the professional trained by the university. However, to confirm these perceptions and to assess the extent to which they occur, new studies are needed pointing in this direction.
\end{abstract}

Keywords: Ombudsman's Office. Bioethics. Public university. Power relationship. 


\section{INTRODUÇÃO}

A representação sobre as relações de poder na universidade, a partir de dados da Ouvidoria de uma instituição federal de ensino superior (IFES), foi o tema de um estudo retrospectivo de manifestações recebidas no período de junho de 2011 a fevereiro de 2015.

As manifestações acolhidas pela Ouvidoria descortinaram as relações de poder estabelecidas entre professores, alunos e servidores administrativos. Aspectos (bio)éticos foram identificados, principalmente nas relações assimétricas de poder, em que a Ouvidoria atuou na mediação de conflitos institucionais.

Considerando a amplitude do tema e os questionamentos apresentados pelos três segmentos, foi feito um recorte para conhecer a representação da relação de poder na universidade articulada pelos alunos. A opção por esse segmento foi influenciada pela expressiva representatividade de manifestações que se coadunam ao tema do estudo quando comparado aos demais - professores e técnicos administrativos.

A participação muito maior dos estudantes do que de outras categorias é um dado nacional, constatado no relatório de todas as outras Ouvidorias universitárias, sendo marcante na UFPB. Os estudantes, em toda a parte, são os que mais se ressentem das insuficiências dos serviços prestados pela instituição, já que são os seus principais usuários. Destarte, constitui o segmento mais distanciado das diferentes formas de exercício do poder na universidade e, não poucas vezes, sujeitos ao mau atendimento e à negligência no desempenho de suas funções. (LYRA, 2000, p.1)

O exercício de acolhimento e mediação de conflitos levados à Ouvidoria por alunos permitem-me corroborar com as observações de Lyra. As situações analisadas em minha prática como Ouvidora oportunizaram-me uma leitura crítica sobre as relações de poder que ocorrem no campo da educação superior, especificamente as que se dão no processo ensino-aprendizagem, motivação do presente estudo. De acordo com MINAYO (2009), embora seja uma prática teórica, a pesquisa vincula pensamento e ação, ou seja, "nada pode ser intelectualmente um problema se não tiver sido, em primeiro lugar, um problema da vida prática".

Considerando o recorte do estudo, foi definido como objetivo geral "conhecer a representação sobre as relações de poder na universidade articulada por alunos que se se manifestaram, via Ouvidoria"; e como objetivos específicos: "definir critérios de bioética para leitura e análise de manifestações que revelam relações de poder"; e "apreender e analisar os questionamentos que denotam relações de poder na ação pedagógica e os possíveis impactos na formação técnica e cidadã do aluno".

$\mathrm{Na}$ análise das manifestações que se coadunam ao tema do estudo, foram detectados aspectos (bio)éticos traduzidos pela vulnerabilidade dos demandantes, assim como por questionamentos que expressavam abuso de poder, violando princípios da justiça e da dignidade humana, entre outros.

Dessa forma, articular a bioética com questões que são suscitadas em uma Ouvidoria universitária remete ao Art. $2^{\circ}(\mathrm{e})$, da Declaração Universal sobre Bioética e Direitos Humanos: "fomentar um diálogo multidisciplinar e pluralista sobre as questões da bioética entre todas as partes interessadas e no seio da sociedade em geral" (UNESCO, 2005). 
No levantamento de estudos sobre Ouvidoria, foram identificadas diferentes abordagens, contudo somente BERTACHINI (2014a) correlaciona os temas bioética e Ouvidoria. Esse estudo não trata especificamente de Ouvidoria universitária, mas faz um breve histórico da evolução da Ouvidoria, examinando os fundamentos da Bioética nas práticas do Ouvidor. Observa uma confluência relevante que proporciona significativos impactos nas discussões éticas, considerando a Bioética da Proteção um instrumento fundamental de suporte reflexivo às Ouvidorias no sentido de se potencializarem como dispositivo social facilitador do diálogo ante os desafios de minimizar as assimetrias de poder e vulnerabilidade. Leva em conta que um projeto para uma nova sociabilidade requer do Ouvidor uma visão ampliada sobre os referenciais bioéticos, transformando-se em um instrumento concreto a mais para contribuir no complexo processo de discussão, emancipação e consolidação das democracias, da cidadania e da justiça social.

Além da Bioética da Proteção, referida por Bertachini, SIQUEIRA et al. (2007) discorrem sobre as características das demais escolas da bioética brasileira: Bioética de Reflexão Autônoma, Bioética de Intervenção, Bioética e Teologia da Libertação, Bioética Feminista e Bioética de Proteção Ambiental. Concluem identificando algumas características comuns às diferentes escolas: 1) defesa do vulnerável; 2) exercício do diálogo; 3) defesa da dignidade da pessoa humana. Pode-se afirmar que a Ouvidoria incorpora as referidas características como valores que humanizam o acolhimento e a tramitação de manifestações para o exercício pleno da cidadania.

A vulnerabilidade é uma característica presente no cidadão hipossuficiente que busca a Ouvidoria para reparar um dano sofrido. O diálogo é um instrumento utilizado pelo Ouvidor para acolher com empatia, estabelecer relação de confiança, na intransigente defesa da dignidade da pessoa humana.

Nesse sentido, Ferrara Júnior e Fernandes destacam o papel da Ouvidoria:

[...] as Ouvidorias constituem-se em um canal de responsabilidade social, resgatando a dignidade da pessoa humana, valorizando e trazendo o indivíduo para o reconhecimento de seus direitos. Sua missão está pautada em valores éticos, morais e no desenvolvimento social. Elas se fortalecem a partir da constatação de que as instituições, públicas e privadas, têm um papel essencial a cumprir, juntamente com os governos e com a sociedade civil, na solução das imensas desigualdades sociais e na falta de solidariedade que aflige o mundo globalizado. (FERRARA JÚNIOR; FERNANDES, 2011, p. 111)

As manifestações foram agrupadas de acordo com as categorias do estudo, sendo analisadas tanto as que receberam tratamento dentro da visão bioética, como as que não foram solucionadas por essa via. A definição das categorias deu-se pela distinção dos campos e dos sujeitos que estavam envolvidos nas relações de poder: na sala de aula entre professor e aluno (ação pedagógica) e em outras instâncias acionadas pelo aluno que não envolviam o professor reclamado no processo decisório.

De acordo com MÜLLER (2002), a relação professor-aluno é uma condição do processo de aprendizagem, pois essa relação dinamiza e dá sentido ao processo educativo. Apesar de estar sujeita a um programa e normas da instituição de ensino, a interação do professor e do aluno forma o centro do processo educativo. A relação professor-aluno pode se mostrar conflituosa, pois se baseia no convívio de classes sociais, culturas, valores e objetivos diferentes. Podemos observar dois 
aspectos da interação professor-aluno: o aspecto da transmissão de conhecimento e a própria relação pessoal entre professor e aluno e as normas disciplinares impostas. Essa relação deve estar baseada na confiança, afetividade e respeito, cabendo ao professor orientar o aluno para seu crescimento interno, isto é, fortalecer suas bases morais e críticas, não deixando a atenção voltada apenas para o conteúdo a ser dado.

Para as questões envolvendo relação de poder em ações pedagógicas, foi oportuno, para fins de análise, separá-las em dois temas: Comunicação interpessoal e Processo ensino-aprendizagem propriamente dito, dando origem a duas subcategorias: O poder na interação professor-aluno e O poder no processo ensino-aprendizagem.

O presente artigo tratará de uma das vertentes das relações de poder na ação pedagógica, mais especificamente a interação entre professor e aluno, fator decisivo para atingir a excelência no processo de ensino e aprendizagem e uma formação plena para a cidadania.

\section{ASPECTOS (BIO)ÉTICOS NA INTERAÇÃO PROFESSOR-ALUNO}

Durante o período do estudo, 2.086 manifestações foram acolhidas pela Ouvidoria da IFES. A amostragem é do tipo não probabilística por conveniência, sendo o tamanho amostral definido por saturação dos dados, de acordo com o recorte do estudo, num total de 77 manifestações classificadas nas seguintes categorias: informação: 4 (5,2\%); reclamação: 29 (37,7\%); denúncia: $44(57,1 \%)$.

Ao analisar o conteúdo das manifestações que constituem o corpus do referido estudo, foram identificadas demandas de alunos que denotam conflitos com professores em sala de aula, envolvendo regras de convivência dentro de um espaço de formação.

As manifestações analisadas explicitavam problemas éticos, contrariando princípios bioéticos, de acordo com a teoria principialista, como autonomia e justiça, assim como em outros aspectos destacados por HOSSNE (2006), em sua proposta sobre os Referenciais Bioéticos, como dignidade, solidariedade, fraternidade, vulnerabilidade, alteridade etc.

Considerando que o ensino universitário visa a capacitação profissional articulada com a formação cidadã, a conduta do professor dentro da sala de aula transmitindo conteúdos relacionados à disciplina que ministra necessita de valores fundamentais ligados à vida, ao seu cuidado, ao trabalho, às relações cooperativas e à cultura da não violência e da paz.

Os relatos dos alunos que se encontravam vulneráveis e privados de justiça por situações que violavam sua autonomia e feriam sua dignidade expressam a representação de poder em relações na universidade. A vulnerabilidade tem se apresentado frequentemente em bioética como um desafio para a ação ética do sujeito autônomo diante de sujeitos vulneráveis. Dessa forma, se entende a vulnerabilidade como sendo "dos outros" e raramente do próprio agente. Daí nasce, certamente, a importante exigência ética quanto à defesa dos sujeitos vulneráveis. Por outro lado, parece deixar na sombra a vulnerabilidade do próprio sujeito da ação (ANJOS, 2006).

Geralmente, quando se tratava de conflito em ação pedagógica, mais precisamente na forma de relacionamento entre professor e aluno, a Ouvidoria fomentava encontro presencial com os 
envolvidos, inicialmente de forma separada e, posteriormente, entre as partes, com mediação da Ouvidora. Dessa forma, vários conflitos foram resolvidos e, assim, medidas extremas, como processos administrativos e judiciais, foram evitadas.

Observa-se que, guardadas as devidas especificidades institucionais, os conflitos relatados pelos alunos se assemelham aos que constam nos relatórios de outras Ouvidorias universitárias no âmbito da educação pública, no contexto da realidade brasileira. Essa homogeneidade pode ser analisada através da teoria sociológica de Bourdieu, que aponta o ensino como um instrumento de reprodução da cultura dominante no ambiente escolar. A escola é vista como um campo que reproduz as desigualdades sociais, seus valores, em vez da função transformadora. Existe uma relação de força, de imposição, que está oculta nas relações pedagógicas aparentemente justas, bem-intencionadas e pacíficas, mas que contribuem para "a transmissão do poder e dos privilégios" nas sociedades capitalistas, daí a concepção de violência simbólica (BOURDIEU; PASSERON, 1992).

Para Bourdieu (1992), toda a ação pedagógica é objetivamente uma violência simbólica enquanto imposição de um arbitrário cultural dominante, que seleciona e legitima a cultura por imposição e inculcação, buscando formar o habitus do indivíduo de acordo com a cultura dominante. Para tanto, se utiliza de uma autoridade pedagógica em que seja possível garantir sua ação, seja por meio de sanções ou naturalizando suas imposições. A ação pedagógica é considerada mais eficaz quanto maior for o prestígio da instituição por ela mediada, bem como o reconhecimento da sua autoridade pedagógica e a proximidade entre a cultura dominante e a cultura vivenciada pelo indivíduo na sua primeira educação.

A representação de poder expressa nas manifestações de alunos à Ouvidoria revela a violência simbólica que ocorre nas relações entre professor e aluno, que, segundo BOURDIEU e PASSERON (1992), seria próprio da ação pedagógica. Os autores afirmam que "o trabalho pedagógico é um substituto da coerção física", pois difunde a ideia de que a violência simbólica exercida pela educação escolar "não tem relação com as relações de força entre os grupos ou classes", quando, na realidade, está difundindo de forma dissimulada os princípios que tornam possível a manutenção das hierarquias existentes na sociedade, como as divisões entre classes sociais proprietárias e não proprietárias dos meios de produção, governantes e governados etc. (PRAXEDES, 2017).

Nos relatos formais e informais descrevendo problemas envolvendo relações de poder, como os que foram expostos no presente estudo, percebe-se a falta de sintonia entre professor e aluno, gerada pela dificuldade em manter uma relação dialógica que permitisse encontrar solução para impasses surgidos, sem necessidade de intervenção externa. Devido ao recorte do estudo, que se propõe a conhecer a representação de alunos sobre o poder na universidade, pôde-se observar que não foram considerados direitos elementares como o de expressão e da escuta empática.

Para FREIRE (1996), ensinar exige disponibilidade para o diálogo ao tratar dos saberes necessários à prática educativa. Tanto professor como aluno aparecem como sujeitos do conhecimento. A realidade é desvelada por ambos, proporcionada pela relação dialógica, tendo a linguagem papel significativo no processo educacional. Também, segundo Freire, são as palavras que possibilitam o diálogo, o encontro entre as pessoas e, sobretudo, a amizade.

A falta de disponibilidade para o diálogo por parte do professor, assim como conduta impositiva 
e desrespeitosa, sem considerar o direito do educando, foram relatadas por alunos à Ouvidoria. $\mathrm{Na}$ exiguidade de espaço para tratar de todos os relatos que apresentavam conflito no processo de comunicação entre professor e aluno, conforme abordado no estudo efetuado, a título de exemplificar, destacamos manifestação intitulada como "agressão verbal, abuso de autoridade, coação, constrangimento, ameaças, dignidade atingida, pressão psicológica e emocional, danos morais".

Segundo o manifestante, a interlocução ocorreu antes do início da aula, de forma amistosa, mas houve alteração por parte do professor quando este fora questionado por ele, o aluno, sobre a não observação da suspensão de aula num período considerado, institucionalmente, sem atividade acadêmica para aquela unidade onde estava sendo ofertada a disciplina. O professor, que pertencia a outra unidade acadêmica onde as atividades não foram suspensas, compareceu à sala de aula e então, com a presença de apenas um aluno, desenvolveu as atividades previstas no cronograma da disciplina, aplicando uma avalição prevista no Plano de Ensino. O manifestante questionou o professor sobre a possibilidade de fazer uma avaliação de segunda chamada para os demais alunos, sendo, nesse momento, tratado de forma agressiva e colocado para fora da sala de aula, sem chance de qualquer entendimento.

Logo após a ocorrência, o manifestante e os demais alunos da turma foram orientados a procurar a Ouvidoria para os devidos encaminhamentos. Observou-se que se tratava de um grupo numeroso, perplexo, em que todos compartilhavam a indignação diante do ocorrido. Após o relato do aluno, corroborado pelos demais, e de algumas ponderações da Ouvidora, os ânimos serenaram. O manifestante, então, foi orientado a formalizar a denúncia para iniciar o processo de mediação do conflito. Como nos demais casos em que o atendimento presencial precedeu o registro formal, este último não conseguiu transmitir os sentimentos externados na oralidade.

Estava explícito o sentimento de injustiça que dominava todos os que presenciaram o fato narrado, assim como o da dignidade atingida, conforme declarado pelo manifestante.

A dignidade da pessoa humana - ainda que carente de conceituação plena e com aceite global - é uma ideia que domina o inconsciente coletivo e universal cuja conscientização surge, mais fluentemente, de sua transgressão. A afetação estética negativa produzida pelo atentado à dignidade humana é de tamanha intensidade que repercute e reverbera em direção inclusive a terceiros não testemunhas diretas do evento danoso. (LIBRELOTTO, 2017, p. 22)

O conceito de dignidade está associado a outros conceitos de forte conteúdo ético: reconhecimento, respeito, liberdade, igualdade e merecimento, que envolvem diversos valores que foram sendo descobertos ao longo da trajetória do homem no mundo (SILVA JÚNIOR et al., 2008).

A atitude de alguns professores em não reconhecer o aluno como sujeito autônomo, tirando-lhe o direito de manifestar seu pensamento, de dialogar, compromete o processo ensino-aprendizagem e o exercício pleno da cidadania. Nesse contexto, o aluno recorria à Ouvidoria, por acreditar ser o caminho mais ágil e seguro de atendimento para reparar um dano sofrido.

Os atores do processo educacional não podem fugir do vir ao encontro do outro, estando de fato existencialmente interconectados. Trata-se, pois, de uma estrutura de alteridade que traz consigo outras reivindicações necessárias à realização do objetivo pedagógico. São elas: tomar o outro a sério; dar atenção às suas perguntas; reconhecer seu direito de receber respostas; e, enfim, com- 
preender sua postura. O entregar-se à presença desafiadora do outro exige, portanto, uma determinada atitude social-ética (FLICKINGER, 2018).

A falta de respeito de professores a direitos garantidos em instrumentos normativos institucionais foi manifestada por alunos que se sentiam impotentes, muitas vezes levando à naturalização dos fatos, ao conformismo e ao descrédito nas instâncias regimentais percorridas.

O desrespeito é solvente poderoso que ataca a capacidade de percepção e evolução da conscientização do homem em relação à sua Dignidade, e a dureza do escárnio dissolve as partículas formadoras dessa consciência. (LIBRELOTTO, 2017, p. 95)

Outro problema identificado em manifestações refere-se ao rebaixamento da capacidade cognitiva e depreciação da potencialidade do aluno pelo professor, assim como o uso de termos pejorativos como, por exemplo, chamar o aluno de "burro". No conteúdo e na forma, o discurso do professor rotulava o aluno de forma negativa e potencializava sua vulnerabilidade.

No cotidiano escolar, é bastante comum alunos como alvos de estigmatização por aqueles que se consideram perfeitos, sejam professores ou seus próprios pares. Qualquer traço que fuja dos padrões "normais" pode levar um grupo ao preconceito e à discriminação, provocando a exclusão do "diferente", e este, muitas vezes, passa a assumir a condição de incapaz, de desacreditado. É possível afirmar, portanto, que a violência simbólica também se dá, nos julgamentos interpessoais que são frequentemente influenciados por estereótipos, que rotulam e estigmatizam os alunos. (BORBA; RUSSO, 2011, p. 33)

Em relato de ocorrência num dos campi instalado no interior do estado, o professor desqualifica o conhecimento dos alunos em sala de aula, usando termos inapropriados para classificar a produção apresentada em seminário por um determinado grupo. Sem oportunizar aos demais grupos a exposição de seu trabalho, estende o julgamento depreciativo para todos e suspende a atividade. $\mathrm{O}$ professor, como condutor do processo ensino-aprendizagem, tem responsabilidade sobre as competências desenvolvidas por seus alunos. Dessa forma, seu comportamento revela falta de bom senso, de autocrítica. Além de ofensivas, as palavras proferidas pelo professor comprometem a autoestima dos alunos ao avaliar de forma pejorativa o trabalho apresentado.

Ao considerar que ensinar exige bom senso, Paulo Freire considera que a vigilância desse bom senso tem uma importância enorme na avaliação que, a todo instante, o professor deve fazer de sua prática.

Ao pensar sobre o dever que tenho, como professor, de respeitar a dignidade do educando, sua autonomia, sua identidade em processo, devo pensar também em como ter uma prática educativa em que aquele respeito, que sei dever ter ao educando, se realize em lugar de ser negado. Isto exige de mim uma reflexão crítica permanente sobre minha prática através da qual vou fazendo a avaliação do meu próprio fazer com os educandos. O ideal é que, cedo ou tarde, se invente uma forma pela qual os educandos possam participar da avaliação. É que o trabalho do professor é o trabalho do professor com os alunos e não do professor consigo mesmo. (FREIRE, 1996 p. 64)

Quando em sala de aula, o professor é dotado de liberdade tal que o tem levado, na maioria das vezes, a adotar uma postura ditatorial perante os alunos, e essa postura tem encontrado amparo no 
fato de que o professor, na sala de aula, tem autonomia para determinar ações, selecionar o conteúdo e a metodologia de ensino, controlar o tempo, enfim, impor aos alunos aquilo que ele acha que é o correto e da maneira que ele quer. Tal postura tem causado desvios no processo de aprendizagem, tirando dos alunos a motivação para participar das aulas e, sobretudo, impossibilitando-Ihes a formação da competência humana, traduzida no saber pensar, no aprender a aprender e na construção e reconstrução do conhecimento. O processo de aprendizagem deve ter como parceiros a incerteza e a dúvida - logo, o professor não é o dono da verdade -, e os alunos, ao lidarem com o conhecimento, devem assumir uma atitude inquieta, curiosa e questionadora, com o uso de estratégias que minimizarão o conflito de poder entre o professor e o aluno, para criar um ambiente propício à formação de cidadãos capazes de pensar, de aprender a aprender e de criar a própria história, individual e coletiva (LIMA, 2013).

Em conflitos narrados à Ouvidoria, a violência simbólica se manifestava através de ameaça de retaliação por parte do professor, utilizada como forma de inibir qualquer reação do aluno à forma de tratamento recebida. Nesses casos a avaliação era usada como instrumento de controle e manutenção do poder, potencializando a assimetria na relação professor-aluno.

Ao longo das últimas décadas, o sistema educativo vem enfrentando uma série de experiências antes desconhecidas, destacadas por Flickinger, que considera que a educação contemporânea está diante de inúmeros desafios para os quais ela ainda não conseguiu respostas e discorre sobre a forma de encarar esses desafios, destacando a autonomia do educando:

A meu ver, o primeiro passo em direção ao manejo desses desafios não deveria consistir na imposição unilateral de normas e compromissos do comportamento social, no intuito de pacificar os respectivos cenários, uma estratégia que domina, até hoje, o espírito educativo. Muito mais importante do que uma inclusão social, custe o que custar, é uma educação que leve a uma postura social capaz de aceitar diferenças, de reconhecer a autenticidade do outro e de assim alcançar a própria maioridade e autonomia do educando. Uma tarefa nada fácil, cujo cumprimento, no entanto, contribuiria para diminuir o desamparo visível do sistema educativo diante da dinâmica de transformações sociais hoje vividas. Como se vê, não se trata de uma reivindicação modesta para a política educacional. (FLICKINGER, 2011, p. 11)

Assim como a competência técnica, a humana também precisa ser aprofundada no processo ensino-aprendizagem. Em relato à Ouvidoria, no qual o aluno sente-se constrangido em sala de aula motivado pelo comportamento do professor, que desacredita publicamente sua competência e potencialidade diante do conhecimento, o aluno declara pretensão de recorrer à instância judicial para a solução do problema. Contudo não o faz, acreditando na competência da Ouvidoria para mediar e solucionar o conflito instalado.

Em vez de subestimar a capacidade do aluno, o professor precisa investir em estratégias, refletidas em táticas e técnicas, que lhe oportunizem maximizar a efetividade do processo interacional na prática escolar. Um dos pontos mais importantes para a realização desse fim é a tomada de consciência por parte do professor de que o conhecimento é construído socialmente, intersubjetivamente, processualmente. Os alunos precisam ser reconhecidos como fundamentais no processo (RIBEIRO, 2002). 
Para que haja esse reconhecimento, é necessário que o professor cultive valores como respeito, humildade e tolerância.

O meu respeito de professor à pessoa do educando, à sua curiosidade, à sua timidez, que não devo agravar com procedimentos inibidores, exige de mim o cultivo da humildade e da tolerância. Como posso respeitar a curiosidade do educando se, carente de humildade e da real compreensão do papel da ignorância na busca do saber, temo revelar o meu desconhecimento? Como ser educador, sobretudo numa perspectiva progressista, sem aprender, com maior ou menor esforço, a conviver com os diferentes? Como ser educador, se não desenvolvo em mim a indispensável amorosidade aos educandos com quem me comprometo e ao próprio processo formador de que sou parte? [...] (FREIRE, 1996, p. 67)

Em narrativa na qual o diálogo não pôde ser estabelecido de forma produtiva, os alunos tentaram argumentar com o professor a forma como os conteúdos estavam sendo ministrados. As avaliações se detinham em memorização de apostilas, desconsiderando as referências bibliográficas apresentadas no plano de ensino da disciplina. O professor em questão foi alvo de várias reclamações e denúncias apresentadas no período do estudo. Cada vez que era citado, ele, espontaneamente, comparecia à Ouvidoria, não para estabelecer diálogo, nem apresentar argumentos sobre as acusações que Ihe faziam. Apresentava, por escrito, resposta já enviada à Ouvidoria por sua chefia imediata, cujo conteúdo não considerava os questionamentos dos manifestantes, mantendo, assim, a mesma rigidez que adotava diante da reclamação dos alunos em sala de aula.

A rigidez pode ser entendida como a adoção de práticas formais, a imposição de conteúdos cristalizados, o culto à "sabedoria" do professor e outras práticas inibidoras da criatividade e da inovação. Nesse sentido, a maleabilidade de conduta possibilita uma maior interação com os alunos, aceitando o erro como condição normal no processo ensino-aprendizagem, permitindo compreender que o professor não é o "dono da verdade". Reconhecer que acumula uma experiência no trilhar os caminhos do saber, tendo o compromisso de orientar e facilitar a aprendizagem, enxergando em seus alunos as características individuais, as múltiplas inteligências e a maneira como elas irão aflorar à medida que forem desafiados a pensar, a problematizar e a buscar respostas próprias com argumentos fundamentados. Estar atento às mudanças da sociedade, garantindo a substituição de velhos por novos paradigmas no processo ensino-aprendizagem. Compartilhar suas ações com os alunos, o trabalho em equipe, as interações tendo como alvo a cooperação, a firmeza e a clareza na expressão de ideologias e convicções, porém consciente de que será necessário mudá-las com o tempo (LIMA, 2013).

Aspectos (bio)éticos estão presentes nas considerações de SILVEIRA (2018) ao destacar que a relação professor-aluno na concepção gramsciana deve ser uma relação humanizada e humanizadora para ambos, de acolhimento e respeito recíprocos, a fim de que o vínculo afetivo e pedagógico entre eles se estabeleça e se consolide, criando uma atmosfera favorável ao ensino e à aprendizagem. Além do mais, a passagem, pelo aluno, do senso comum ao saber elaborado, científico, impõe ao professor pelo menos duas ordens de exigências que não se desvinculam: uma que poderia ser denominada de técnico-profissional e outra ético-política. A exigência técnico-profissional se refere à qualificação para o trabalho pedagógico, a qual supõe um duplo domínio: do saber a ser 
ensinado e das mediações didáticas apropriadas para que ocorra a aprendizagem. De acordo com FREIRE (1996), o professor deve estar consciente que saber ensinar não é transferir conhecimento, mas criar as possibilidades para a sua própria produção ou a sua construção.

Quanto à exigência ético-política, por sua vez, remete a um conjunto de opções pessoais do professor: por exemplo, recusar o autoritarismo e o pedantismo; minimizar a distância que naturalmente o separa dos alunos; despojar-se, mesmo que momentaneamente - numa espécie de ironia socrática -, de seu próprio saber, para que aflore o saber do educando; derrubar os alambrados que protegem o saber escolar do assédio das massas; renunciar a se tornar guru, para ser mestre, isto é, mistagogo, que desmistifica e esclarece o que parecia misterioso; enfim, aproximar-se do aluno com simplicidade e humildade, mostrando-se disposto a acompanhá-lo no processo de aprendizagem (SILVEIRA, 2014).

Nem sempre essas exigências técnico-profissional e ético-política foram observadas por professores em relatos de alunos à Ouvidoria, mas é corroborada por FREIRE (1996), ao afirmar que:

Assim como não posso ser professor sem me achar capacitado para ensinar certo e bem os conteúdos de minha disciplina, não posso, por outro lado, reduzir minha prática docente ao puro ensino daqueles conteúdos. Este é um momento apenas de minha atividade pedagógica. Tão importante quanto ele, o ensino dos conteúdos, é o meu testemunho ético ao ensiná-los. É a decência com que o faço [...] (FREIRE, 1996, p. 103)

Outras questões, além das apresentadas acerca do processo comunicacional entre professor e aluno, são objetos de análise sobre as relações de poder na ação pedagógica do citado estudo. Trata-se do poder no processo ensino-aprendizagem, envolvendo a não observação das normas e dos valores regimentais.

\section{CONSIDERAÇÕES}

O professor autoritário, o professor licencioso, o professor competente, sério, o professor incompetente, irresponsável, o professor amoroso da vida e das gentes, o professor mal-amado, sempre com raiva do mundo e das pessoas, frio, burocrático, racionalista, nenhum desses passa pelos alunos sem deixar sua marca. (FREIRE, 1996, p. 66)

Ao considerar a amplitude do estudo realizado, os relatos dos alunos à Ouvidoria estão em conformidade com os conflitos que ocorrem na ação pedagógica em outras instituições de ensino superior.

No recorte do presente artigo, assim como nas demais categorias do estudo, as questões reclamadas pelos alunos estão contempladas em estudo realizado por COLETA e MIRANDA (2003) sobre as manifestações de alunos universitários caracterizadas como assédio moral. Os autores destacam, dentre elas, agressão verbal: uso de termos pejorativos e palavras de baixo calão; intimidações: ameaçar de reprovar a turma, expulsar o aluno etc.; comentários depreciativos, preconceituosos ou indecorosos; rebaixamento da capacidade cognitiva: comparar, de forma irônica, os próprios alunos com estudantes de outras instituições de ensino ou grupos de ensino; ridicularizar erros em provas e trabalhos; ler, em voz alta, as notas, enfatizando, com comentários depreciativos, os alunos que 
obtiveram baixo rendimento; fazer comentários em público sobre as dificuldades, desempenho ou erros dos alunos; uso inadequado de instrumentos pedagógicos: aplicar prova com prazo mais curto do que o necessário para resolvê-la; aumentar o nível de dificuldade das questões como forma de punição; realizar atividades valendo nota em dias que alunos, por motivo justo, não puderam estar presentes; recusar-se a ensinar, negar-se a esclarecer dúvidas, alegando que a pergunta é desnecessária ou que já havia explicado a questão antes.

Nesse sentido, durante o período do estudo, a Ouvidoria constituiu-se num importante canal de comunicação entre alunos e as instâncias competentes, com o compromisso de estabelecer a verdade para reparar danos e injustiças que ocorreram na ação pedagógica, protegendo a parte vulnerável através do sigilo, impedindo retaliações àqueles que buscavam direitos amparados na missão e em valores institucionais.

Embora se reconheça que o vínculo entre professor e aluno é assimétrico, em princípio considerado natural em relacionamentos que não são entre iguais, a mediação de conflitos pela Ouvidoria permitiu que práticas autoritárias que potencializavam a assimetria de poder fossem avaliadas, corrigindo o uso inadequado dessa condição. Dessa forma, foi possível reparar injustiças apresentadas através de manifestações, resgatando a autoestima e a cidadania de alunos que buscavam a Ouvidoria como espaço de acolhimento.

Entretanto ainda existem casos subnotificados que expressam violência simbólica na ação pedagógica, mas são legitimados pelo próprio educando. A violência simbólica é exercida nas relações de comunicação entre os professores, detentores da autoridade pedagógica para realizar a ação pedagógica. A autoridade pedagógica de um professor depende do reconhecimento que lhe é dado pelos estudantes, e é ela que garante a legitimidade para coordenar os processos de ensino e aprendizagem que ocorrem no cotidiano escolar. Para que isso ocorra, os educadores buscam manter uma relação de comunicação com os estudantes "que dissimule as relações de força que a tornam possível" (BOURDIEU; PASSERON, 1992). A relação professor-aluno deixa de aparecer como uma relação de força e passa a ser vista como uma relação puramente pedagógica de formação educacional dos estudantes e, portanto, legítima, pois aparentemente não é realizada através da coerção física, da autoridade e da violência simbólica dos educadores (PRAXEDES, 2015).

Dentre as percepções advindas dos relatos dos alunos, pode-se concluir que, assim como a qualidade do ensino define a capacitação técnica do educando, também a postura do educador influenciará em sua formação humana, com impactos em sua vida profissional. Identificar em que intensidade isso ocorre requer um novo estudo apontando nessa direção.

\section{REFERÊNCIAS}

ANJOS, Márcio Fabri. Vulnerabilidade como parceira da autonomia. Revista Brasileira de Bioética. São Paulo: v. 2 , n. 2, 2006.

BERTACHINI, Luciana. Fundamentos da Bioética na atuação de Ouvidoria. Tese apresentada ao Programa de Pós-Graduação em Bioética do Centro Universitário São Camilo. São Paulo, SP, 2014a. 
BORBA, Joyce Falcão; RUSSO, Maria José de Oliveira. Contradições na escola: a violência no lugar do desenvolvimento humano. Revista Múltiplas Leituras, v. 4, n. 2, 2011.

BOURDIEU, Pierre; PASSERON, Jean-Claude. A reprodução: Elementos para uma teoria do sistema de ensino. 3. ed. Rio de Janeiro: Francisco Alves, 1992.

COLETA, José Augusto Dela; MIRANDA, Henrique Carivaldo Neto de. O rebaixamento cognitivo, a agressão verbal e outros constrangimentos e humilhações: o assédio moral na educação superior. Revista da Associação Nacional de Pós-graduação e Pesquisa em Educação. 26 ed., 2003.

FERRARA JÚNIOR, Carlos; FERNANDES, Jonadir Aparecida Galvão. A Ouvidoria e a Garantia de Direitos do Cidadão. In: PEREZ, Roberto Rus; BARREIRO, Adriana Eugênia Alvim; PASSONE, Eric (Org.). Construindo a Ouvidoria no Brasil: avanços e perspectivas. Campinas, SP: Unicamp/Ouvidoria, 2011.

FLICKINGER, Hans-Georg. Autonomia e reconhecimento - dois conceitos-chave na formação. Revista Educação, Porto Alegre, v. 34, n. 1, 2011.

Educação e alteridade em contexto de sociedade multicultural. Cadernos de pesquisa, v. 48, n. 167, 2018.

FREIRE, Paulo. Pedagogia da Autonomia: saberes necessários à prática educativa. São Paulo: Paz e Terra, 1996.

HOSSNE, William Saad. Bioética - Princípios ou Referenciais? Mundo da Saúde, v. 30, 2006.

LIBRELOTTO, Gicélia. Dignidade da pessoa humana: reflexões jurídicas e filosóficas sobre o conceito. 2017. Dissertação (Mestrado em Filosofia) - Escola de Humanidades da Pontifícia Universidade Católica do Rio Grande do Sul.

LIMA, Oséas Felício. Conflitos de poder entre professor e aluno. Administradores.com. 2009.

LYRA, Rubens Pinto. Coluna do Ombudsman. Multidéias, 2000. Disponível em: http://fnou.com.br/site/assets/publicacoes/ufpb_artigos_multideias.pdf. Acesso em: 17 nov. 2017.

MINAYO, Maria Cecília de Souza (Org.). Pesquisa Social. Teoria, método e criatividade. 18 ed. Petrópolis: Vozes, 2009.

MÜLLER, Luiza de Souza. A interação professor-aluno no processo educativo. Integração, n.3, ano VIII, 2002.

PRAXEDES, Walter. A educação reflexiva na teoria social de Pierre Bourdieu. São Paulo: Edições Loyola, 2015.

A violência simbólica dos sistemas de ensino e a reprodução da ordem social. WordPress, 2017. Disponível em: https://walterpraxedes. wordpress.com/2017/10/25/a-violencia-simbolica-dos-sistemas-de-ensino-e-a-reproducao-da-ordem-social. Acesso em: 23 jan. 2018.

RIBEIRO, Luiz Freire. A relação de poder na sala de aula: em busca de positividades. 2002. Disponível em: http:// www.gelne.com.br/arquivos/anais/gelne-2002/ artigos/04_linguistica_aplicada/artigo40.pdf. Acesso em: 13 mar. 2017.

SILVA JÚNIOR, Walter J; HOSSNE, William Saad; SILVA, Franklin Leopoldo. Dignidade Humana e Bioética: uma abordagem filosófica. Bioethikos, v. 2, n. 1, 2008.

SILVEIRA, René Trentin. A relação professor-aluno de uma perspectiva gramsciana. Educação \& Realidade, v. 43, n. 1, Porto Alegre, 2018.

SIQUEIRA, José Eduardo; PORTO, Dora; FORTES, Paulo Antonio de Carvalho. Linhas temáticas da Bioética no Brasil. In: ANJOS, Marcio Fabri; SIQUEIRA, José Eduardo (Org.). Bioética no Brasil: tendências e perspectivas. São Paulo: Ideias \& Letras; São Paulo: Sociedade Brasileira de Bioética, 2007.

UNESCO. United Nation Educational, Scientific and Cultural Organization. The Universal Declaration of Bioethics and Human Rights. 2005. Disponível em: http://unesdoc.unesco.org/images/0014/001461/146180por.pdf. Acesso em: 12 jan. 2017. 